\title{
The New Orientalism: The Influence of Media Representation of 'the Other' in International Affairs
}

\author{
Gavan Patrick Gray \\ Department of Policy Studies, College of Policy Studies, Tsuda University, \\ Tokyo, Japan \\ Corresponding author. E-mail: gray@tsuda.ac.jp \\ https://doi.org/10.12982/CMUJASR.2018.0007
}

\begin{abstract}
The concept of Orientalism refers to the distorted manner in which Eastern people and cultures are often viewed by the West. Despite long awareness of this tendency it persists in modern media. However, its focus shifts depending upon which states are perceived by Western governments as presenting the most significant threat to their dominance of international affairs. In recent years Russia and China have begun to supplant the Islamic world as preeminent among such perceived threats. This paper argues that a pattern of media reporting exists which limits views of such states in a way that generates a shallow and stereotypical conception of its people. The danger in this is that, lacking a well-rounded view of the people and culture of such states, the use of force becomes more easily framed as a necessity amongst other policy options, rather than a choice of absolute of last resort.
\end{abstract}

Keywords: Security, Media, Orientalism, Propaganda, China, Russia.

\section{INTRODUCTION}

At the end of the Cold War there seemed to be a growing consensus that the West, in its victory over the U.S.S.R., had proven the superiority of the liberal democratic system over that of authoritarianism with authors such as Fukuyama (1992) arguing that we would soon see a shift from competing political structures to a global order based around a clearly dominant system. These claims now seem presumptuous, and in recent years a different thesis has arisen which views the very foundations of liberal democracy as being under threat, specifically from the authoritarian nature of the Russian 
and Chinese political systems. These arguments are not new but they have taken on greater force in the wake of what some perceive as a weakening of Westerndemocracy following the 2016 Brexit referendum in the UK and subsequent presidential election in the USA.

Since then warnings of this dual threat to the West's civic foundations have been common both in book form (Mosher, 2017; Snyder, 2018) and in the popular press (Diamond, 2016; Caryl, 2018). Of course, this is far from the first time that the West has given into an existential fear that its civilization was threatened by the East. It was the distorted nature of this fear that first gave rise to the field of Orientalism in the nineteenth century, and for one of its key proponents in the twentieth century to warn that:

Every single empire in its official discourse has said that it is not like all the others, that its circumstances are special, that it has a mission to enlighten, civilize, bring order and democracy, and that it uses force only as a last resort. (Said, 1979, xvi)

It is beyond the scope of this paper to determine the extent to which either Russia or China do or do not pose a threat to liberal democracy. Rather, it is the reaction to these perceived, or projected, threats that is assessed. There is an inherent risk, with threats that come from beyond our in-group, that both the danger and most suitable response will be evaluated not purely through rational assessment of the existing dangers but will instead, to some extent, be influenced by the divergence of the 'other' from our own self-identity. In evaluating the Russian and Chinese threats, therefore, it is vital that they not be viewed through a 'dehumanizing' filter that would remove our ability to relate to them as fellow human beings.

Nonetheless, we find that this is precisely what occurs, with mainstream media depiction of these states neglecting to present stories that highlight their cultural depth and common humanity, and focusing heavily on the leaders of rival states as a figurative embodiment of their state as a whole. The danger of such patterns is that the use of force becomes easier to accept as a necessary punishment for states that are seen as both morally and culturally inferior to our own.

This paper examines the development of the concept of Orientalism and its evolution into a new, modern form that focuses on the states currently challenging Western political supremacy. It 
then examines the nature of the media filter through which these challengers are represented to the Western public and provides the results of research into the patterns exist in such representations. Finally, these results are used to support an argument that the biased and crude manner in which these states are framed helps to promote easier public acceptance for aggressive military responses against the states in question.

\section{ORIENTALISM}

The concept of Orientalism developed as European states pushed further into the Middle and Far East during the $18^{\text {th }}$ and $19^{\text {th }}$ centuries. The scholars who began to examine the culture of these, to the European mindset, foreign people became known as 'Orientalists' and acted as the filter for how the majority of Europeans would perceive the subjects of their study. It was only in 1979 that Edward Said, in his book Orientalism, began to use the term as a theory of critical analysis which argued that these filters had created a grossly distorted image of Asian societies that focused on their extremes, rendering them as sensual, barbaric, emotional, and primitive; overlooking their complexity and their ties to the underlying foundations of rational, scientific thought which support any great civilization.

These distorted views were influenced and exaggerated by emotional undercurrents of superiority and fear that existed within European society. The former expressed itself in the concept of the White Man's Burden', the name taken from a Rudyard Kipling Poem which argued that Europe was the pinnacle of human development and bore a responsibility for lifting the 'lesser' races out of their perceived uncivilized states (Kipling, 1899). These sentiments can be seen in the words of G. Stanley Hall, President of Clark University in 1903:

My plea is that Indians, who are men of the stone age, and other low races should first be sympathetically studied, as we study children; then shall we first not try to eradicate the tribal system, but graft something better on its vigorous stock (Hall, 1903).

The other aspect was embodied by the concept of the 'Yellow Peril', a belief that countries such as India and China, simply by virtue of their far greater populations, posed an existential threat to Western 
civilization and would, unless action was taken, overwhelm both the European people and their culture. The target of this fear was capable of shifting as necessary, with Japan, despite its adoption of European institutions and values during the Meiji period, being seen by some as the foremost threat following their victory in the Russo-Japanese War of 1904 (Lusk, 1907). During the twentieth century the focus would continue to shift following events such as the Communist Revolution in Russia, the Pacific War, the Iranian Revolution, China's Cultural Revolution, and the ebb and flow of the Cold War.

Russia too, by dint of its Slavic culture was also considered 'outside' Western European civilization. A factor highlighted in Samuel Huntington's Clash of Civilizations (1996), which foresaw inevitable existential conflict between the major world cultures. While Huntington included among these major cultures a Slavic, or 'Orthodox' civilization, his main concern was the danger of the Islamic world and rising East Asian economic power. Following the events of $9 / 11$ and the beginning of the War on Terror, his views on the former seemed especially prescient and there was a renewed focus on the dangers of the Middle East that only exacerbated decades of negative stereotyping of Arabic people This, in turn, gave rise to a Neo-Orientalism which sought to look at how modern perceptions of the Middle East were being effected by current events (Tuastad, 2003; Samiei, 2010).

The War on Terror was, however, marked by a change in the way the public viewed the nature of threats. Societal fear has always been a key element of political manipulation, as highlighted by Mencken (1922) when he stated, "the whole aim of practical politics is to keep the populace alarmed (and hence clamorous to be led to safety) by menacing it with an endless series of hobgoblins, most of them imaginary". It remained as such during the 1990s when, despite increases in relative levels of security and safety in the West, the sense of fear experienced by the public was maintained by a steady stream of manipulative media stories focusing on outlier crimes and insignificant dangers (Glassner, 2004). Nonetheless, during this period fear was tied to specific issues whose threat level rose or fell in distinct waves. The use of fear during the War on Terror differed in that, unlike previous wars, there was no clear objective, clearly defined enemy, or prospective end in sight (Altheide, 2006). In 2018 alone the USA was involved in combat in fourteen different countries as part of this ongoing, perpetual campaign against 'terror' (Savell, 2019) and the constant war footing 
has created an expectation both that attacks on the West might occur at any time, and that military responses to such threats are a natural and ongoing part of everyday affairs. This, needless to say, does very little to reinforce the view that use of military force should be the policy option of last resort.

\section{A NEW ORIENTALISM}

In 2009 a shift was taking place in Western strategic priorities. In that year Hillary Clinton presented Russian Foreign Minister Sergei Lavrov with a symbolic 'reset button' intended to issue in a new age of US-Russian cooperation. The rationale behind this was that the US had recognized the possible threat inherent in China's sudden and dramatic economic growth, a factor which led to the US enacting a strategic 'pivot to Asia' (Manyin, 2012). This was complicated though, by Western efforts (primarily the USA, the UK and France) to make use of the 2010 Arab Spring to increase their political influence in the Middle East and North Africa. Russia opposed such military intervention in Libya, but without success. However, when the Western states moved to support efforts to remove the Assad government in Syria, Russia took more direct action to prevent it. Needless to say, the US-Russian rapprochement had foundered and Russia, alongside China, were now key targets for political and media messages regarding the threats each posed to Western civilization.

It may seem extreme to paint simple strategic opposition or economic growth as such existential threats but this is not a question of reality but rather one of public perception. Negative stereotypes of both Russians (Ibroscheva, 2002) and Asians (Hassan, 2018) have been common in the West for decades, a factor which makes it relatively easy for the media to frame them within the preexisting and persistent patterns of fear. In the case of Russia and China this has taken the form of a clear campaign to paint both states as direct threats to the foundational norms of Western Liberal Democracy, a message that appears widely in relation to both the defense of political principles and strategic interests. Recent examples of these patterns are provided by Habets (2015) and Chabra (2019).

In regard to the former, there are arguments to be made that the success of liberal democracy, as a developmental and economic model, represents the greater threat to authoritarian states, who are likely to liberalize as an unintended consequence of mimicking 
Western patterns. Additionally, it might be said the true threat to the liberal values the West espouses is the normative impact of policies that place military force before the alternative paths offered by diplomacy and international law. In terms of strategic interests, however, it is the perception of threats, rather than their existence, which is used to justify aggressive responses to the rising states that currently challenge Western economic and military omnipotence. These distorted perceptions are produced in large part by the ways in which the mass media filters our knowledge and understanding of the states in question.

\section{THE FILTER}

The first element of this system involves creating a figure through which the pervasive atmosphere of fear and unease can be given physical form. These media-crafted homunculi are exaggerated versions of real people that may bear superficial resemblance to the actual version but which exist in a world of extremes of behavior and black and white clarity. In the past we have seen versions take the form of Hussein, Milosevic, Gaddafi, Ahmajinedad, and Kim. Media effigies that are capable of generating either fear, revulsion, hatred or mockery as political and economic needs dictate.

The latest and most prominent in this long list of 'enemies of the West' is Russian President Vladimir Putin, a figure who has acted as a target for Western animosity for quite some time. In his analysis of media coverage of Putin during the Ukraine Civil War and the annexation of the Crimea, McLaughlin (2016) states: “The language used to depict the Russian leader and his actions and policies during the crisis produced a profile that if based on a clinical examination might justify a split diagnosis of a condition ranging from paranoidschizophrenia to psychopathy". Headlines repeatedly refer to Putin as thuggish, cold, cruel, and calculating, images in keeping with preexisting stereotypes of Russian men. In the West the tabloid papers focused more on simple, snappy headlines designed to provoke knee-jerk responses, while the broadsheets focus more on analysis that paints him as a Bond villain come to life (McLaughlin, 2016).

Often the first step in such a process is to compare the target to previous boogeymen. The UK's Daily Mail gave a great example of this with a full front page headline in which Britain's Prince Charles proclaimed Putin to be, 'Just like Hitler' (English, 2014). Repeated demonization of the target is followed by attribution of unforgivable 
crimes. Again the Daily Mail stepped up by offering, "Putin's killed my son", another front page headline juxtaposing these claims with a 'coincidentally' placed image of a cherubic toddler. This photograph was not the 'son' referred to in the article, who was in fact a twenty year-old man (Dolan, 2014).

Such alleged crimes are often given front page banners that are intended to invoke extreme emotional responses without providing any insight or deeper understanding of the complexity, or accuracy, of the actual situation. Headlines such as, "Now, they're Gassing Children" (Hughes, 2013), which widens the scope of blame to that of a vague, nebulous 'they', effectively encompassing an entire nation, are followed by a stream of similar accusations, such as 'Assad Gassing Kids Again' (Hughes, 2017), and 'You Animal Assad' (Glaze, 2018), with the result that when military action is promoted as being, 'A Strike at the Heart of Evil' (Sunday Express, 2018), the public is willing to abrogate their moral responsibility and stand back, or even applaud, missile strikes which, as any rational analysis will suggest, are quite likely to result in exactly the same kind of civilian casualties that they had purportedly been horrified by.

It is this public acceptance of sudden violent reprisals, which is the final goal of the New Orientalism in media. There is an ongoing filter in play that creates, whether through deliberate design or unintentional outcome, a perception of Eastern states and their culture as being incapable of responding to anything less than brute force. These 'target states' are presented in the news in a two-dimensional manner that, like earlier Orientalism, focuses only on specific aspects, framing them in terms of political, military or economic issues, rather than in more human terms. The result is that Western audiences are led to view such states as monolithic, impersonal structures headed by a caricature of a dictator, rather than complex collections of living, breathing citizens, most of whom have no connection to the actions of their government.

\section{METHODOLOGY}

To examine Western coverage of Russia and China, the New York Times (USA) and the Guardian (UK), two papers typically seen as liberal or left-leaning in their editorial policy, were used for analysis. In both cases the general tone of coverage regarding the target states was quite negative. Numerous critical stories featuring each state were balanced by a relatively equal number of neutral pieces. Positive stories, however, 
were, in Russia's case, restricted entirely to the 2018 World Cup, and in China's to potential benefits of economic growth. For the purpose of this article, rather than carrying out a subjective assessment of the degrees of negativity involved, an analysis of thematic content was judged to be more reliable. It has been said that the power of the media lies not in its ability to influence our thoughts but rather in its ability to influence the subjects we think about. With this in mind, the key question was how were the two countries more generally framed in relation to specific subjects.

The analysis used a series of Lexis-Nexis searches for articles strongly focused on the target states, specifically articles with the country name appearing in the headline itself. The search covered a two-year period from April 2017 to March 2019. It excluded articles focusing on major sporting events (such as the 2018 Football World Cup, 2018 Pyeongchang Winter Olympics, and the upcoming 2019 Rugby World Cup) as these created a marked distortion in regular article dispersion and can be considered to represent a focus on the events more than the target states. A third country, Japan, was selected as a basis for comparison due to its role as an 'Eastern' state perceived to be a Western ally.

Articles were assigned a thematic focus from one of the following categories: economics, politics, security, authoritarianism, science, sport, culture and news. The 'authoritarian' category was created to focus on purely negative political stories involving censorship, abuse of human rights, and other acts of oppression. The 'news' category acted as a catchall for stories which did not clearly fall into other categories. Two additional categories were created to account for a specific focus on two ongoing stories that generated a significant amount of media attention. The first were claims of Russian interference in US politics, and the second, allegations of Russian doping in sports (Table $1 \& 2$ ).

A second series of Lexis-Nexis searches was carried out to examine the media's propensity for focusing their attention on Heads of State rather than the state itself. In this case stories featuring the state name in the headline were compared with stories which instead featured the Head of State's name during the same period. The newspapers examined were the New York Times and the Guardian, representing broadsheets, and the Daily Mail and the Daily Mirror, representing tabloid press. Comparisons were made between Vladimir Putin, Kim Jong Un, Salman bin Abdulaziz Al Saud, and Shinzo Abe (Table 3). 


\section{RESULTS}

The primary results (Table 1) reveal that coverage of Russia is dominated by political and security issues, as well as the claims of interference in the US 2016 election. Coverage of these topics in the New York Times amounted to, respectively, 32.9\%, 15\% and 34\% of the total. Along with stories focused on authoritarianism $(4.5 \%)$, this accounted for $86.4 \%$ of the overall stories. In comparison the stories focusing on what might be considered the more human aspect of the state: science, sports and culture, were featured only $0.4 \%, 1.2 \%$ and $3.2 \%$ of the time. A similar pattern held true for the Guardian, with politics, economics, security, authoritarianism and election interference representing $88 \%$ of stories and the three more human categories only $5.6 \%$.

Table 1. Thematic coverage of articles from 1 April 2017 - 31 March 2019.

\begin{tabular}{lccccccccc}
\hline & Total & Politics & Economics & Security & Auth. & News & Science & Sport & Culture \\
\hline NYT & & 381 & 14 & 133 & 40 & 13 & 4 & 11 & 28 \\
Russia & 854 & $(32.9 \%)$ & $(1.6 \%)$ & $(15 \%)$ & $(4.5 \%)$ & $(1.5 \%)$ & $(0.4 \%)$ & $(1.2 \%)$ & $(3.2 \%)$ \\
Guardian & & 233 & 9 & 238 & 44 & 27 & 2 & 23 & 29 \\
Russia & 950 & $(24.5 \%)$ & $(0.9 \%)$ & $(25 \%)$ & $(4.6 \%)$ & $(2.8 \%)$ & $(0.2 \%)$ & $(2.4 \%)$ & $(3 \%)$ \\
\hline NYT & & 493 & 510 & 89 & 248 & 75 & 28 & 8 & 104 \\
China & 1,560 & $(31.6 \%)$ & $(32 \%)$ & $(5.7 \%)$ & $(15.8 \%)$ & $(4.8 \%)$ & $(1.8 \%)$ & $(0.5 \%)$ & $(6.6 \%)$ \\
Guardian & & 347 & 247 & 36 & 188 & 48 & & 30 & 52 \\
China & 979 & $(35.4 \%)$ & $(25.2 \%)$ & $(3.6 \%)$ & $(19.1 \%)$ & $(4.8 \%)$ & $28(2.8 \%)$ & $(3.6 \%)$ & $(5.3 \%)$ \\
\hline NYT & & 55 & 48 & 12 & 0 & 43 & 3 & 19 & 74 \\
Japan & 262 & $(21 \%)$ & $(18.3 \%)$ & $(4.5 \%)$ & - & $(16.4 \%)$ & $(1.1 \%)$ & $(7.2 \%)$ & $(28.2 \%)$ \\
Guardian & & 61 & 30 & 14 & 2 & 55 & 5 & 23 & 69 \\
Japan & 265 & $(23 \%)$ & $(11.3 \%)$ & $(5.2 \%)$ & $(0.7 \%)$ & $(20.7 \%)$ & $(1.8 \%)$ & $(8.6 \%)$ & $(26 \%)$ \\
\hline
\end{tabular}

Note: Two special categories exist for Russian coverage: Election Interference (NYT = 291 stories, 34\%) (Guardian 314, stories 33\%) and Sports Doping (NYT 32 stories, 3.7\%) (Guardian 29 stories, 3\%).

In coverage of China, there was a marked difference. Whereas Russia's dominant categories had been politics, security and election interference, China's were politics, economics and authoritarianism. Including security these made up $85.1 \%$ of stories in the New York Times and $82.9 \%$ in the Guardian. Stories in the three more positive categories amounted to $8.9 \%$ in the New York Times and $11.7 \%$ in the Guardian.

The imbalance becomes clear when we consider results for Japan. Politics, economics, security and authoritarianism amount to $43.8 \%$ 
of coverage in the New York Times and 39.5\% in the Guardian. There are a far higher amount of more neutral 'news' stories on topics such as crime and natural disasters. Meanwhile the three positive categories amount to $36.5 \%$ in the New York Times and 36.4\% in the Guardian.

Table 2. Ratio of stories featuring state-oriented themes (political, economic, security, authoritarianism) versus those featuring human-oriented (sports, science, culture).

\begin{tabular}{lcc}
\hline & State-oriented & Human-oriented \\
\hline NYT Russia & $19: 1$ & \\
Guardian Russia & $16: 1$ & \\
NYT China & $9: 1$ \\
Guardian China & $7: 1$ \\
NYT Japan & $1.2: 1$ \\
Guardian Japan & $1.1: 1$ \\
\hline
\end{tabular}

Looking at the ratio for coverage of the first group of more state-oriented categories (politics, economics, security, authoritarianism and election interference) against the three more human-oriented categories, the results are, for Russia, 19:1 (New York Times) and 16:1 (Guardian); for China, 9:1 (New York Times), and 7:1 (Guardian); for Japan, 1:1 (New York Times), and 1:1 (Guardian) (see Table 2 for details).

Table 3. Ratio of headlines featuring state name versus head of state.

\begin{tabular}{lcccc}
\hline & Russian / Putin & North Korea/Kim & Japan / Abe & Saudi Arabia / Salman \\
\hline New York Times & $3: 1$ & $4: 1$ & $20: 1$ & $700: 1$ \\
The Guardian & $3: 1$ & $1.6: 1$ & $10: 1$ & $100: 1$ \\
The Daily Mail & $1.4: 1$ & $1: 1.7$ & $100: 1$ & $50: 1$ \\
The Daily Mirror & $3: 1$ & $1: 1.3$ & $100: 1$ & $100: 1$ \\
\hline
\end{tabular}

Note: For Saudi Arabia, 'Saudi' was used as the search string due to numerous headlines referring to state affairs in this way. Using only 'Saudi Arabia' stills produces a ratio significantly higher than those of other states.

The secondary results (Table 3) suggest that for states perceived as significant security threats to the West (Russia and North Korea), there is a much stronger focus on the actions and role of the head of state (Vladimir Putin and Kim Jong Un) than there is for states such as Japan which are seen as allies. In the case of Russia there was a consistency in coverage by the New York Times and the Guardian, 
with both using headlines referring to the state three times more often than they did Putin. With North Korea there was a marked divergence, with the Times referring to the state four times more often than its leader, while the Guardian did so only 1.6 times as often, a much stronger leader-oriented view. The extent of this leader-focus in regard to North Korea is clear when we compare their coverage of Japan, with the New York Times being twenty times more likely to refer to the Japanese state than its leader, and the Guardian ten times more likely. Additionally, the tabloid newspapers appear to follow these patterns to an even greater extent than the broadsheet papers. In the case of North Korea, their headlines are actually more likely to refer to the leader than they are the state itself, while both broadsheets only ever referred to Japan by its state name rather than through the persona of its leader.

\section{DISCUSSION}

The filter presented by media coverage exists on a number of levels; however, the scope of this article focuses only on two aspects: the lack of complexity, and the lack of humanity. In the first instance the presentation of the state in the form of a monolithic entity leads to the reduction of its human component, in terms of citizenry and culture, to a single representative individual. This figurehead, as we have seen has been the case with figures such as Putin, Assad, Kim, Hussein, becomes an easy target for media demonization. The danger lies in the possibility that by presenting this figure as both representative of the state, and as a personification of clear black and white morality, it becomes easy for the media's audience to come to view the state itself, and by extension the citizens of that state as extensions of this clear black and white morality. This tendency is exacerbated by the second element of sidelining representation of the wider population and their culture and instead focusing only on affairs of state: security, politics, economic issues, etc.

There is strong evidence that these patterns are likely to produce greater acceptance for military action, especially if framed as a 'just' act of retribution for moral transgressions. Berinsky (2007) found that citizens are most strongly influenced by elite attitudes, typically expressed through mass media promotion of the opinions of professed policy experts, in deciding whether to support or oppose military action. When these messages are framed in terms of good versus evil, or as confronting a foreign villain, there is an even stronger tendency to offer unconditional support (Liberman, 2006). These patterns are tied to our deep-seated 
distrust of 'the other', especially when tied to a sense of anger or hostility (Kim, 2014). Additionally, when the 'out group' is perceived as a cohesive whole there is a heightened desire to achieve retribution or inflict punishment (Liberman \& Skitka, 2019). Clearly these patterns can only be enhanced by both media personification of the state as a whole in the form of the all powerful leader, and through the lack of awareness of the diversity and humanity of the state's citizenry that exists as a side effect of distorted and imbalanced thematic framing of the state in question.

The analysis here clearly shows certain trends at play in how different states are covered. Despite each state's importance in world affairs they are treated differently by the media. This is, of course, perfectly natural as, depending upon their size, relationships and policies, they will play different roles, and have a greater or larger impact on specific areas of news because of this. In other words, it is understandable, to an extent, that an imbalance in fields of coverage exists. Nonetheless, the manner in which they are represented will have an impact on public perceptions and these will, in turn, have an impact on how the public responds to calls for aggressive military or political responses to the states in question, potentially making such military responses more tempting as a first, rather than last, response.

From the results, there appears to be a clear correlation between a state's status as either threat or ally and its media representation. In the case of Japan, there is a significantly higher focus of media attention on cultural stories that reflect the more human or natural aspects of the country, and an inversely weak tendency to focus on its leader. In this case, Shinzo Abe, the Prime Minister of Japan, is not simply a temporary state leader. He has been in power longer than the five preceding Prime Minister's combined and was Japan's preceding Prime Minster before those five took power. He is, by far, the most dominant figure in twenty-first century Japanese politics yet he is comparatively rarely the focus of Western reporting on his country despite his involvement in a number of political scandals that might have further justified such attention. The argument might be made that, unlike Putin and $\mathrm{Xi}$, Abe is not an authoritarian leader. Yet in the same two year period, King Salman of Saudi Arabia, a Western ally despite his authoritarian rule, features just once in headlines from the New York Times (a 300:1 ratio against headlines featuring the state name) and five times in the Guardian (a 40:1 ratio). 
In the same manner, Japan's general populace, its social issues and its culture receive greater attention despite the fact that both China and Russia have equally rich, vibrant societies capable of providing ample fodder for interesting and illuminating articles. Even in regard to more neutral 'news' stories, focusing on criminal events, natural disasters or reporting of unusual occurrences, there is a clear discrepancy in the amount of coverage Japan receives in comparison to the other states.

It is hard to say whether such trends are a deliberate pattern designed to produce specific reactions in the audience or an unconscious bias that exists within the media itself, leading them to shy away from the investigation of and reporting on more human-oriented news regarding countries commonly perceived as threats. The reasons for the tendency among journalists and their host organizations to do this is something that might be examined in future research. The important factor is that a bias in the presentation of these countries does exist and it is one that is likely to contribute to the adoption of more two-dimensional, monolithic, institutionally-oriented perceptions of the states in question that exacerbate the natural tendency of audiences to view foreign nations with a higher level of suspicion and moral certitude than they do their own. As such, in times of high tension, where the possibility of military conflict between the West and these states becomes a real possibility, the patterns employed by the media in such coverage are likely to allow military options, which should always be a last recourse, to be adopted with greater ease and acceptance than they otherwise might.

The institutions of the media have a powerful and important role, both within their host societies and beyond. They have the power to promote greater understanding and awareness among the states of the world by highlighting the appeal of foreign cultures, and the social patterns that reveal the common bonds of humanity that are shared by diverse people. That the media is moving in a different direction that limits such awareness-raising solely to states viewed as political allies is not simply a missed opportunity for enhancing global stability and peace, but a dangerous trend that is likely to increase the likelihood of future conflicts by seizing upon military action as a justifiable default response to perceived transgressions, rather than a policy of last resort. 


\section{REFERENCES}

Altheide, D.L. (2006). Terrorism and the politics of fear. New York: Rowman and Littlefield.

Berinsky, A.J. (2007). Assuming the costs of war: Events, elites, and American public support for military conflict. The Journal of Politics, 69(4), 975-997.

Caryl, C. (2018, March 28). Yes Russia's out to get us but don't forget the Chinese. Washington Post.

Chabra, T. (2019, February). The China challenge, democracy, and U.S. grand strategy. The Brookings Institute.

Diamond, L. (2016, December 9). Russia and the threat to Liberal Democracy.The Atlantic.

Dolan, A. (2014, July 19). Putin's killed my son. The Daily Mail.

English, R. (2014, July 19). Charles: Putin behaving just like Hitler. The Daily Mail.

Fukuyama, F. (1992). The End of History and the Last Man. New York: Free Press.

Glassner, B. (2004). Narrative techniques of fear mongering. Social Research,71(4), 819-826.

Glaze, Ben. (2018, April 9). You Animal Assad. The Daily Mirror.

Habets, I. (2015). Liberal democracy: the threat of counter-narratives. European View, 14(145).

Hall, S.G. (1903). The white man's burden versus indigenous development of the lower races. The Journal of Education, 58(4).

Hassan, A. (2018, June 23). Confronting Asian-American stereotypes. New York Times.

Hughes, C. (2013, August 22). Now they're gassing children. The Daily Mirror.

- (2017, April 5). Assad gassing kids again.The Daily Mirror.

Huntington, S.P. (1996). The Clash of Civilizations and the Remaking of World Order. New York: Simon \& Schuster.

Ibroscheva, E. (2002). Is there still an evil empire? The role of the mass media in depicting stereotypes of Russians and Eastern Europeans. Global Media Journal, 1(1).

Kim, D. (2014). Affect and public support for military action. SAGE Open, pp. 1-13.

Kipling, R. (1899). The white man's burden. Text available via Fordham University. Retrieved from https://sourcebooks.fordham.edu/ mod/kipling.asp 
Liberman, P. (2006). An eye for an eye: Public support for war against evildoers. International Organization, 60(3), 687-722.

Liberman, P. \& Skitka, L. (2019). Vicarious retribution in US public support for war Against Iraq. Security Studies, 28(12), 189-215.

Lusk, H. (1907). The real yellow peril. The North American Review, 186 (624), 375-383.

Manyin, M.E., Daggett, S., Dolven, B., Lawrence, V.S., Martin, F.M., O'Rourke, R. \& Vaughn, B. (2012, March 28.) Pivot to the Pacific? The Obama administration's 'rebalancing' toward Asia. Congressional Research Service.

McLaughlin, G. (2016). The war correspondent. New York: Pluto Press.

Mencken, H.L. (1922). In defense of women, New York: Alfred A. Knopf.

Mosher, S.W. (2017). Bully of Asia: Why China's dream is the new threat to world order. New York: Regency.

Said, E. (1979) Orientalism. London: Penguin Books 2003.

Samiei, M. (2010) Neo-Orientalism? The relationship between the West and Islam in our globalizedworld. Third World Quarterly, 31(7), 1145-1160.

Savell, S. (2019, January) This map shows where in the world the U.S. military is combatting terrorism. Smithsonian magazine.

Shaheen, J.G. (2003). Reel bad Arabs: How Hollywood vilifies a people. The Annals of the American Academy of Political and Social Science, $588,171-193$.

Snyder, T. (2018). The road to unfreedom: Russia, Europe, America. New York: Tim Duggan Books.

Sunday Express (2018, April 18). A strike at the heart of evil. The Sunday Express.

Tuastad, D. (2003). Neo-Orientalism and the new barbarism thesis: Aspects of symbolic violence in the Middle East conflict(s). Third World Quarterly, 24(4): 591. 